\title{
HUMAN INFECTIONS WITH THYMINE-REQUIRING BACTERIA
}

\author{
Rosalind Maskell, O. A. Okubadejo, R. H. Payne* and Linda Pead \\ Public Health Laboratory, St Mary's Hospital, Portsmouth, and ${ }^{*}$ LKB Instruments Ltd, \\ 232 Addington Road, South Croydon, CR2 $8 Y D$
}

\section{Plate IV}

Co-TRimoxazole (Septrin, Bactrim), a combination of sulphamethoxazole (SMX) and trimethoprim (TMP) in a ratio of $5: 1$, has been available for clinical use in this country since 1968; it acts by sequential blockade of bacterial tetrahydrofolate synthesis. It is effective against Gram-negative and Grampositive organisms, and is widely used for the treatment of urinary-tract and chest infections. It is also employed in low dosage for long-term prophylaxis or suppression of urinary-tract infection (Cattell et al., 1971; Smellie et al., 1976). Since 1972 there have been several reports of the isolation of thymineor thymidine-requiring mutants of bacteria from patients undergoing treatment with co-trimoxazole (Barker, Healing and Hutchison, 1972; Lacey and Lewis, 1973; Okubadejo and Maskell, 1973; Tanner and Bullin, 1974; Tapsall, Wilson and Harper, 1974; Hayek and Netherway, 1976).

We reported briefly on three patients seen during 1971 and 1972 who were infected with such mutants (Okubadejo and Maskell, 1973); since then, 16 other patients with mutant infection have been identified in this laboratory. Thirteen had urinary-tract infection, one had a nephrostomy infection, one had a nephrectomy-wound infection, and one had chronic chest infection All had been treated with co-trimoxazole. In a preliminary report on six of these patients (Maskell, Okubadejo and Payne, 1976), it was shown that the mutants grew in satellitism with wild-type organisms, and that the urine contained a thymine-like compound that might support their growth in vivo. We now present a fuller account of this work, together with the clinical details of the 16 patients, and the bacteriological characters of the organisms.

\section{MATERIALS AND METHODS}

Isolation and initial examination of organisms. Routine urine cultures were made by plating a standard 0.01-ml loopful on CLED medium (Mackey and Sandys, 1966). Wound swabs were cultured on blood agar, electrolyte-deficient agar (Sandys, 1960) and MacConkey's agar. Sputa were cultured on PNF blood-agar medium (Lowbury, Kidson and Lilly, 1964), chocolate agar, and electrolyte-deficient agar, after homogenisation with $\mathrm{N}$-acetyl cysteine. Sensitivity tests were performed by the flood-plate method on Diagnostic Sensitivity Test (DST, Oxoid) agar (Iso-Sensitest, Oxoid, since April 1976) enriched with $10 \%$ lysed horse blood. Organisms were identified by standard methods (Cowan and Steel, 1966).

Received 12 Apr. 1977; revised version accepted 19 July 1977. 


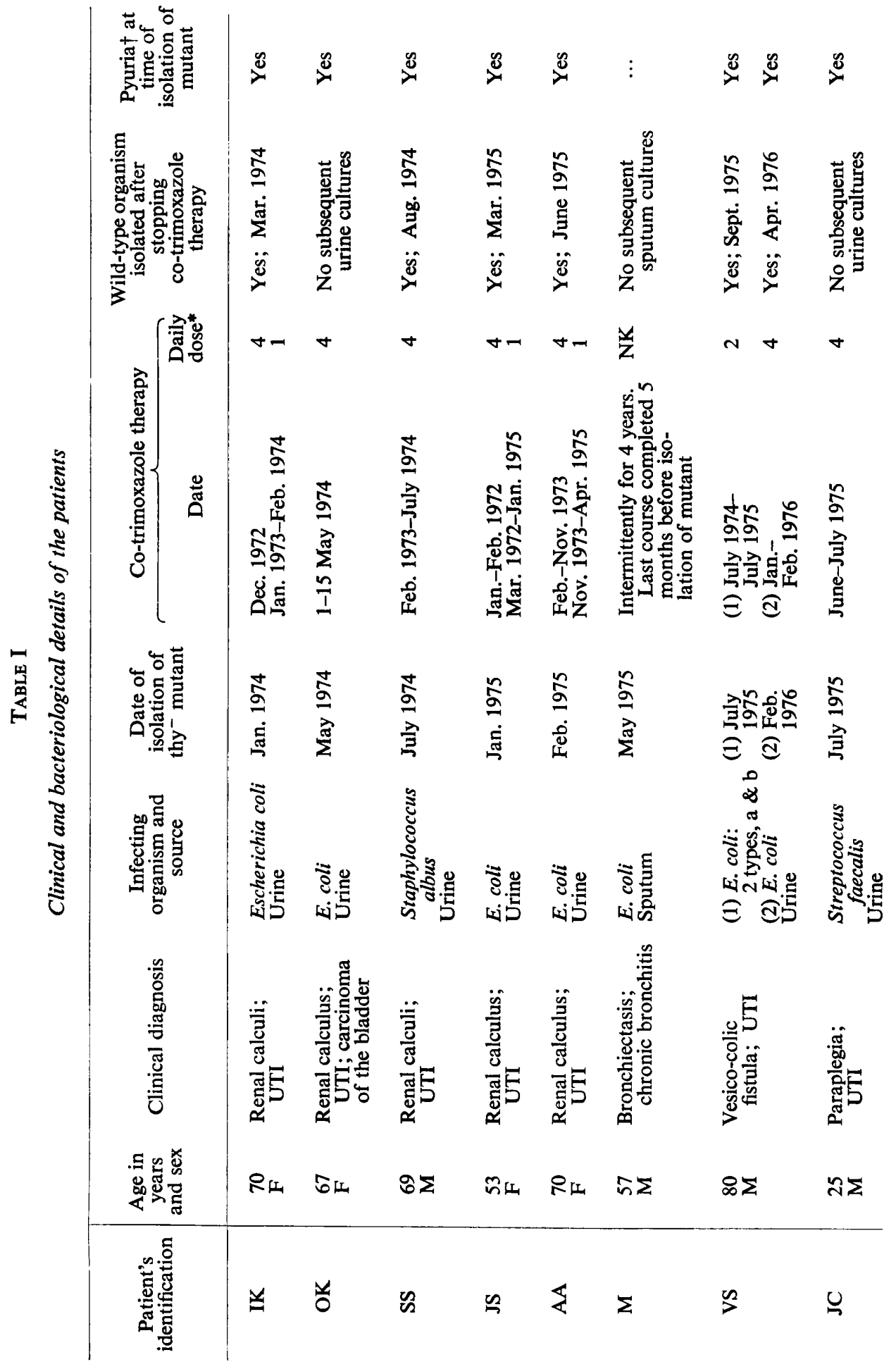




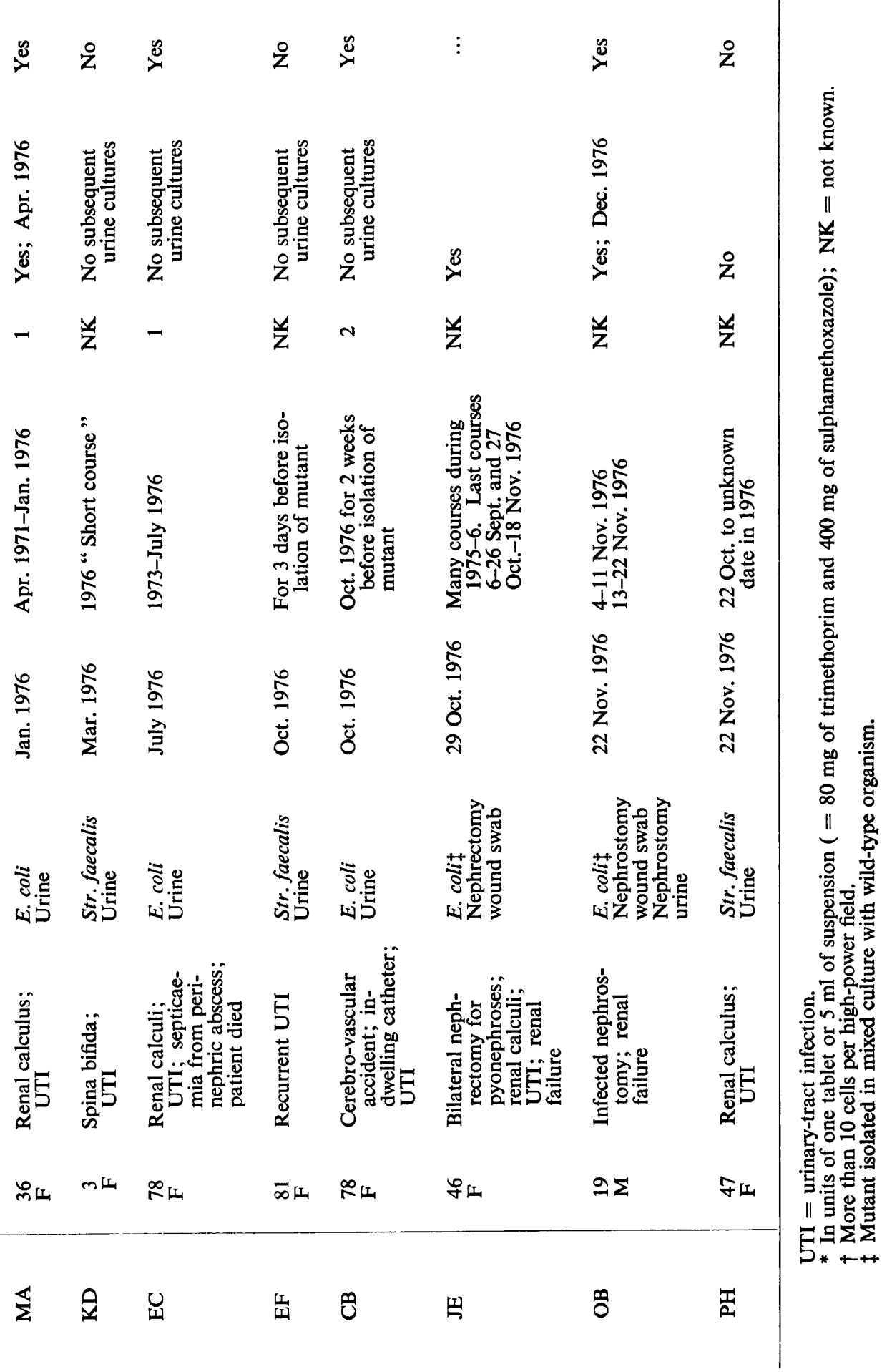


Nutritional requirements of the mutants were determined by the use of minimal-salts agar as described by Clowes and Hayes (1968). Escherichia coli strains W3110 (thymine-requiring, supplied by Dr Naomi Datta. Royal Postgraduate Medical School, London) and NCTC10418 (prototroph) were used as controls. Organisms that failed to grow on minimal-salts enriched with $250 \mu \mathrm{g}$ of thymine per ml were plated on Iso-Sensitest agar (IS) and blotting paper disks containing $2 \mu \mathrm{g}, 20 \mu \mathrm{g}$ and $200 \mu \mathrm{g}$ of thymine were placed in the centre of the plates. All plates were incubated at $37^{\circ} \mathrm{C}$ for $48 \mathrm{~h}$.

"Satellitism" tests. A loopful of a turbid suspension in physiological saline of $E$. coli strain NCTC10418 was spread on one half of a plate of minimal-salts agar. The other half was inoculated from a colony of the mutant organism. Control plates were inoculated with cultures of the mutants alone. All plates were incubated at $37^{\circ} \mathrm{C}$ and examined after $48 \mathrm{~h}$ and 5 days. The organisms that did not grow in satellitism with $E$. coli on minimal-salts agar were re-tested on IS agar. The mutant organism from one patient was also tested for satellitism with a wild-type organism isolated from her urine on a different occasion.

Analysis of urine samples for thymine and thymidine-like compounds. Urine samples previously reported upon were analysed by the cation-exchange method (Maskell et al., 1976). Urine samples from two other patients and two control specimens of normal urine were examined by isotachophoresis (Arlinger, 1971; Everaerts and Becker, 1976), which is a quicker and simpler procedure. These analyses were carried out in an LKB2127 Tachophor (LKB

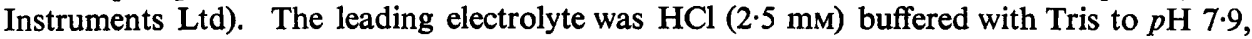
and containing hydroxy-propyl-methyl cellulose $0.3 \% \mathrm{w} / \mathrm{v}$. The terminating electrolyte was $\beta$-alanine $(20 \mathrm{~mm})$ buffered with barium hydroxide to $p \mathrm{H} 10 \cdot 6$. The separation was carried out at $20 \mu \mathrm{A}$ at a temperature of $20^{\circ} \mathrm{C}$. The UV absorbance was measured at $280 \mathrm{~nm}$. One $\mu l$ of urine was taken for analysis, and each sample was examined with and without the addition of $10 \mathrm{ng}$ of a thymine standard. The total analysis time was $35-40 \mathrm{~min}$. per sample.

\section{RESULTS}

\section{Patients}

Details of the age, sex, diagnosis, infecting organisms and treatment of the patients are shown in table I. One patient had a chest infection; one had an infected wound after nephrectomy for pyonephrosis and renal calculi; one other patient had an infected nephrostomy; eight patients had renal calculi and urinary-tract infection; four had urinary-tract infection in situations predisposing to chronic sepsis, and one had recurrent cystitis. Nine patients had received long courses of co-trimoxazole, from several months up to 5 years. Seven had had continuous and two had had intermittent treatment. The other seven patients had received short courses of one month or less, and one patient(VS) who had previously received a long course had a recurrence of mutant infection after a subsequent short course of treatment. All the patients from whom mutants were isolated from the urine and the patient with wound infection were undergoing treatment at the time the isolation was made; the patient with mutant chest infection, however, had received no co-trimoxazole during the 5 months before the isolation of the mutant.

\section{Bacteriological characteristics of the organisms}

The mutants were initially identified by their failure to grow on DST or IS agar in routine sensitivity tests, and this finding was confirmed at least twice for each organism. All urinary organisms grew on CLED agar; all except those from patients JE and OB showed normal colonial morphology and had a 
THYMINE-REQUIRING BACTERIA

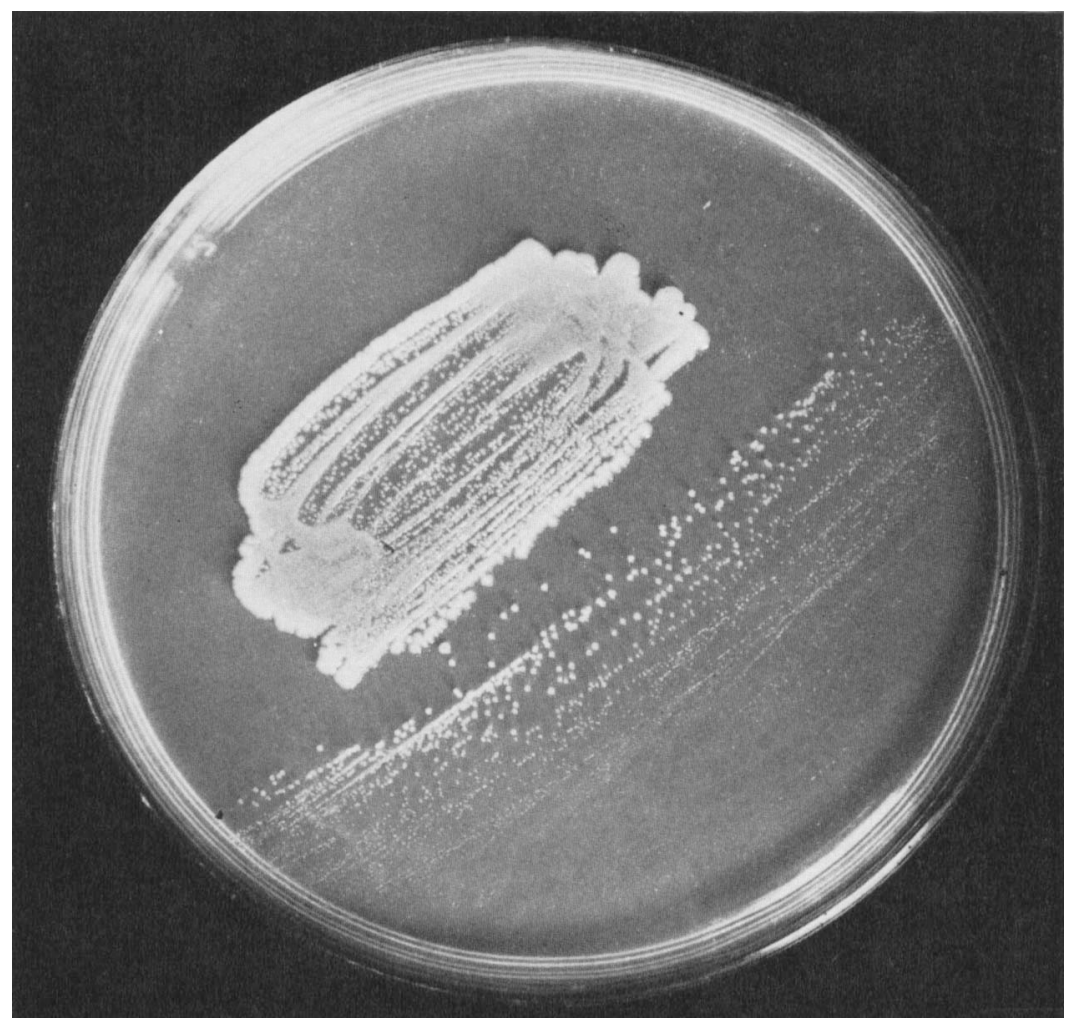

FIG. 1.-Mutant growing " in satellitism " with wild-type Escherichia coli. 
normal appearance on Gram's staining. Those from patients JE and OB showed poor growth on CLED agar, and had a long filamentous appearance on Gram's staining. The mutant isolated from patient MA apparently reverted to the wild-type in vitro, and therefore its thymine requirements could not be determined.

The nutritional requirements for thymine are shown in table II. None of the mutants grew on minimal-salts agar alone; 11 grew if amounts of thymine varying from $0.25 \mu \mathrm{g}$ per $\mathrm{ml}$ to $250 \mu \mathrm{g}$ per $\mathrm{ml}$ were added. The remaining organisms (four strains of Streptococcus faecalis, one strain of Staphylococcus albus and one late lactose fermenting strain of $E$. coli (strain VS(1)b) failed to grow on minimal-salts agar even after the addition of thymine $250 \mu \mathrm{g}$ per ml. However, they all grew well on IS agar around a thymine disk. The four strains of Str. faecalis grew with low-content $(2 \mu \mathrm{g})$ disks; the other two required high-content $(200 \mu \mathrm{g})$ disks. It was concluded that these organisms required not only thymine but also some other unidentified substance or substances present in IS agar and in CLED agar. Thus, six of the organisms (strains IK, SS, M, VS(1)b, JE and OB) were found to have a high thymine requirement, and needed a concentration greater than $2.5 \mu \mathrm{g}$ per ml or grew only around a high-content disk. Four of the corresponding patients (IK, SS, M and VS) had been treated with long courses of co-trimoxazole before the isolation of the mutant organism; in this respect, and in their clinical characteristics, they resembled the three patients from whom we originally isolated mutants during 1971-2 (Okubadejo and Maskell, 1973). The remaining two organisms with a high requirement (from patients $\mathrm{JE}$ and $\mathrm{OB}$ ) were isolated during the first few days of co-trimoxazole therapy, and their colonial and morphological appearances suggested that their thymine requirements were not adequately supplied. Eleven organisms (from 10 patients) had a low thymine requirement. Patients AA, EC, JS and VS (at the time of the first isolation) had received long courses of co-trimoxazole and were clinically similar to the patients reported upon in 1973 and to four of those in the high-requirement group. The other seven organisms were isolated after short courses of co-trimoxazole. With the exception of the mutant isolated from patient OK, none was isolated after a short course of therapy until the middle of July 1975, and since then such isolations have been occurring with increasing frequency.

\section{Satellitism}

Thirteen mutant organisms were tested for growth " in satellitism" with $E$. coli strain NCTC10418; the mutant from patient AA was also tested with a wild-type strain of $E$. coli isolated from her urine on a different occasion. The results of these tests are shown in table III (see also fig. 1).

With the exception of strain JE, all the mutant organisms that had grown on minimal-salts agar with the addition of thymine showed growth in satellitism with E. coli no. NCTC10418, and that from patient AA with her own wild-type organism. In addition, the organism VS(1)b showed poor growth under these conditions. The organisms that had a low thymine requirement 
38 ROSALIND MASKELL, O. A. OKUBADEJO, R. H. PAYNE AND LINDA PEAD

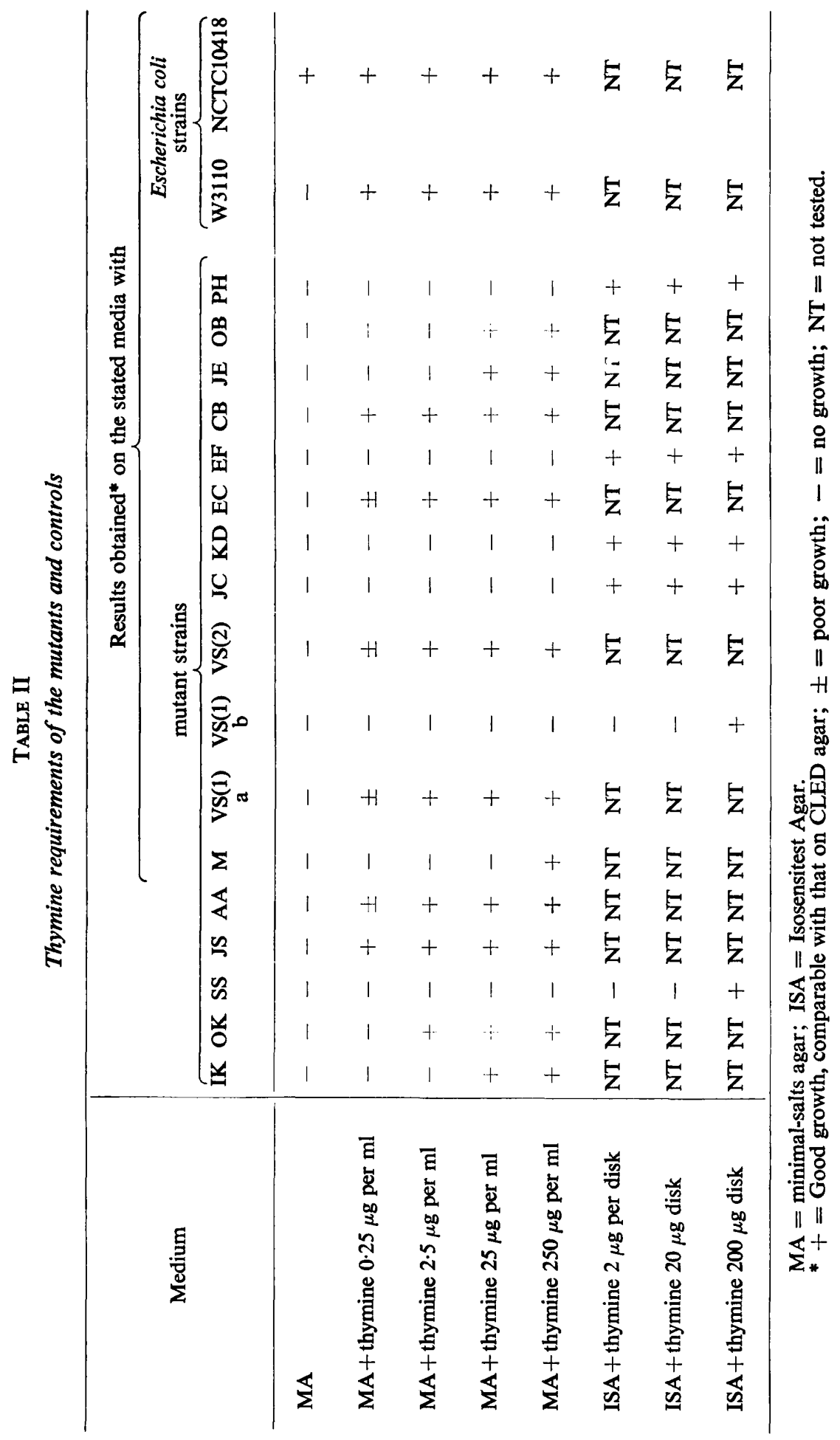


TABLE III

Satellitism when thy- mutants were grown on the same plate as a wild-type Escherichia coli strain*

\begin{tabular}{|c|c|c|c|c|}
\hline \multirow{3}{*}{ Mutant } & \multicolumn{4}{|c|}{ Amount $\dagger$ of growth of the mutant on } \\
\hline & \multicolumn{2}{|c|}{ minimal-salts agar } & \multicolumn{2}{|c|}{ Isosensitest Agar } \\
\hline & after $48 \mathrm{~h}$ & after 5 days & after $48 \mathrm{~h}$ & after 5 days \\
\hline IK & \pm & + & NT & NT \\
\hline JS & + & + & NT & NT \\
\hline $\begin{array}{l}\text { AA (with strain } \\
\text { NCTC10418) }\end{array}$ & + & + & NT & NT \\
\hline $\begin{array}{l}\text { AA (with patient's } \\
\text { wild-type strain) }\end{array}$ & + & + & NT & NT \\
\hline VS(1)a & + & + & NT & NT \\
\hline VS(1)b & \pm & \pm & NT & NT \\
\hline $\mathrm{JC}$ & - & - & + & + \\
\hline KD & - & - & + & + \\
\hline $\mathrm{EC}$ & \pm & \pm & NT & NT \\
\hline $\mathrm{EF}$ & - & - & + & + \\
\hline $\mathrm{CB}$ & + & + & NT & NT \\
\hline $\mathrm{JE}$ & - & - & - & - \\
\hline OB & - & \pm & NT & NT \\
\hline PH & - & - & + & + \\
\hline
\end{tabular}

* Except where stated otherwise, this was strain NCTC10418.

$\dagger+=$ Good growth (positive satellitism); $\pm=$ poor growth (positive satellitism); $-=$ no growth (negative satellitism); NT $=$ not tested.

Controls: in each experiment, the thy ${ }^{-}$mutant failed to grow on the corresponding medium in the absence of the wild-type strain.

(strains JS, AA, VS(1)a and CB) grew well after incubation for $48 \mathrm{~h}$, whereas the organisms with a high requirement grew less well (strains IK, VS(1)b and OB) or not at all (strain JE). The only exception was strain EC, which had a low requirement but showed only poor growth. Five of the six organisms that required another factor in addition to thymine were tested for satellitism on minimal-salts agar; only one (strain VS(1)b) showed any growth. The others (strains JC, KD, EF, PH) grew well in satellitism when IS agar was used as the culture medium.

\section{Analysis of urine for thymine- and thymidine-like compounds}

Under the conditions described for the first method (Maskell et al., 1976), thymidine had a retention time of $40 \mathrm{~min}$. and thymine was detected after 72 
min. (fig. 2). Both components absorbed ultraviolet light strongly at 254 and $280 \mathrm{~nm}$. Urine samples from patients IK, SS, JS and AA were examined; all contained a component that was detected after 72 min., indicating the presence of a thymine-like compound. The peak heights on the chromatograms were measured and compared with the peak produced by a standard sample of thymine $(20 \mu \mathrm{g})$. The concentrations of thymine-like compound were $15 \mu \mathrm{g}$, $10 \mu \mathrm{g}, 10 \mu \mathrm{g}$ and $25 \mu \mathrm{g}$ per $\mathrm{ml}$ respectively. Samples of urine from three healthy adults and from two patients with acute urinary-tract infection and pyuria did not show this component. However, the urine from a patient with renal calculi who had had co-trimoxazole therapy for 12 months, but from whom mutant organisms had never been isolated, had a concentration of $20 \mu \mathrm{g}$ per ml. Figs. 3-5 are examples of the tracings.

Urine samples from patients VS and JC were examined by isotachophoresis. They were found to contain concentrations of a thymine-like compound of c. $5 \mu \mathrm{g}$ and $10 \mu \mathrm{g}$ per $\mathrm{ml}$ respectively; this component was not detected in two control specimens of normal urine examined by the same method.

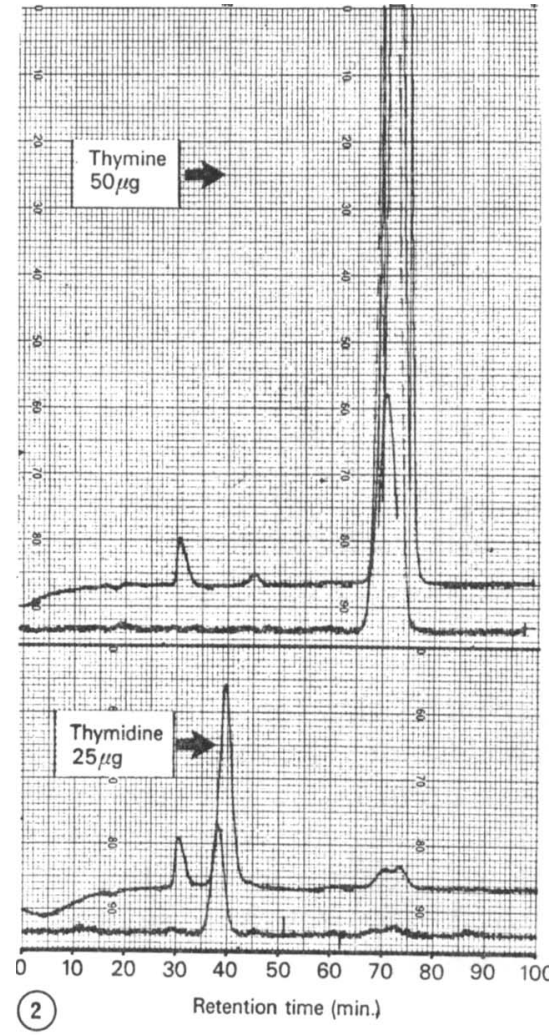

(2)

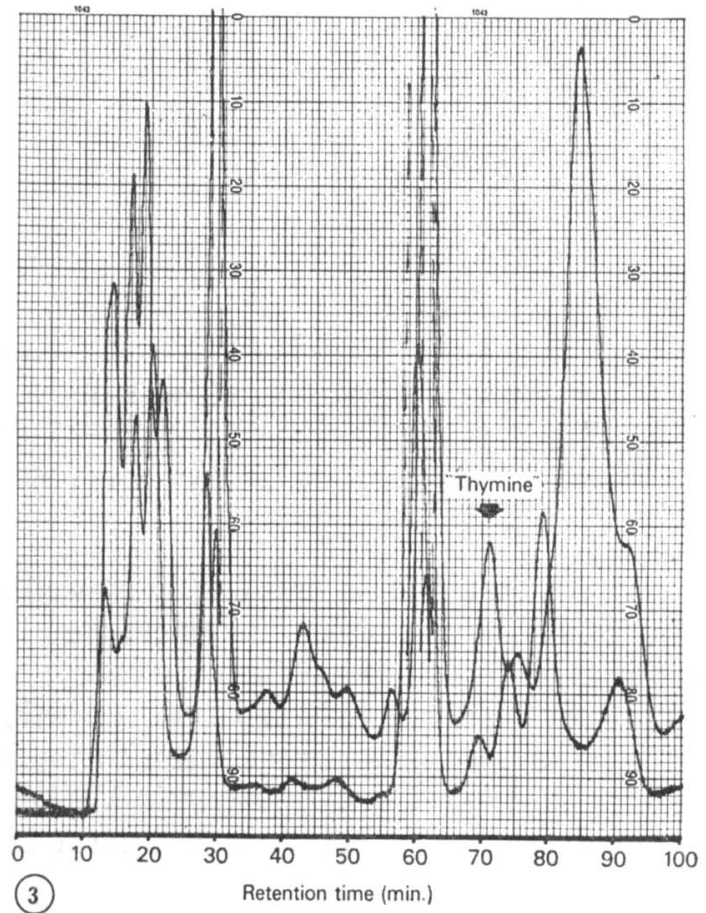

(3)

FIG. 2.-Thymine and thymidine standards; UV absorbance at 254 and $280 \mathrm{~nm}$.

FIG. 3.- " Thymine" peak in urine of patient infected with thy mutant; UV absorbance at 254 and $280 \mathrm{~nm}$.

(FIGs. 2-5 show the results of tests performed by the method of Maskell et al. [1976].) 

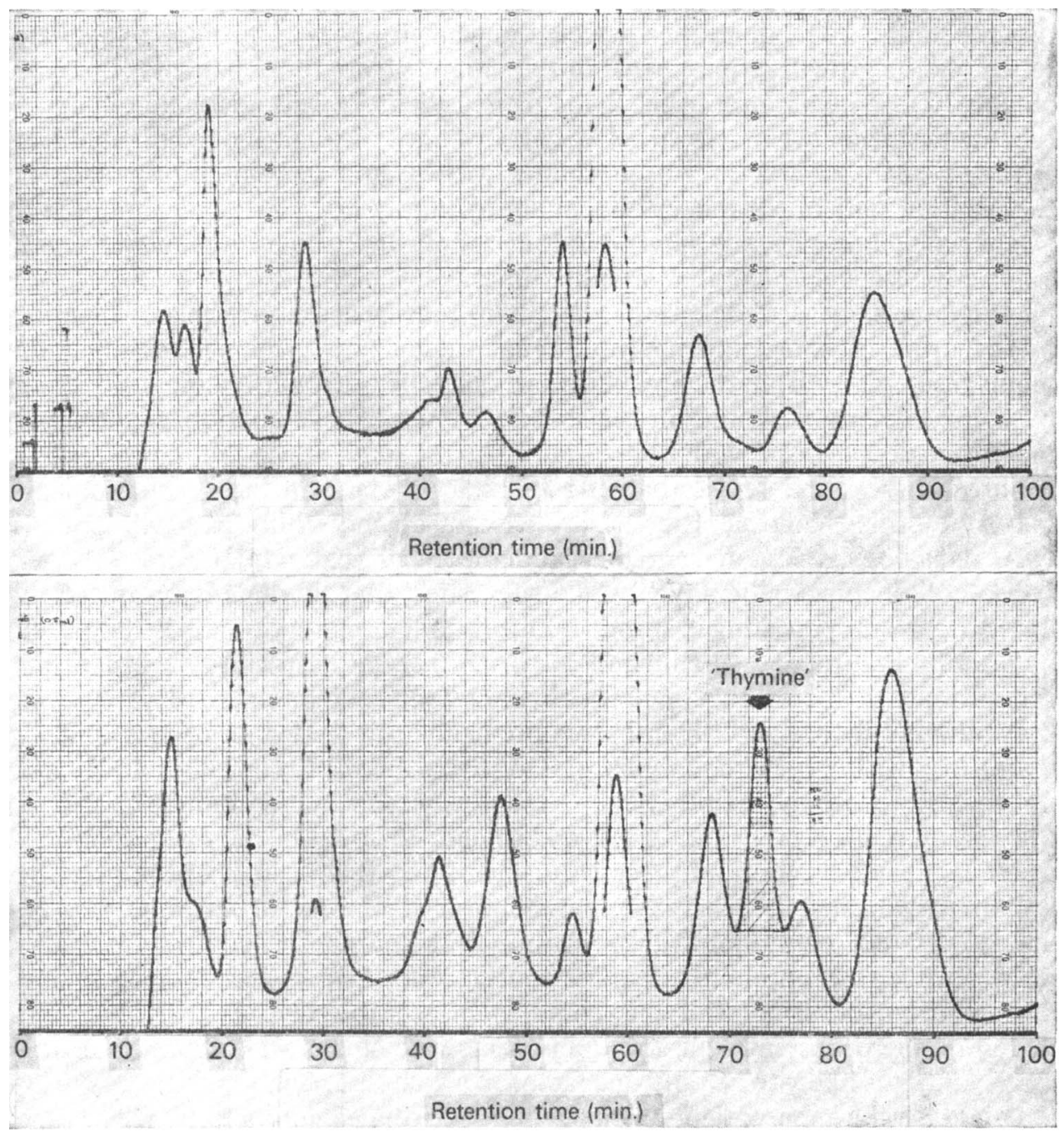

FIG. 4 (above).-Normal urine with no " thymine "peak; UV absorbance at $280 \mathrm{~nm}$.

Fig. 5 (below).-Normal urine to which thymine had been added; UV absorbance at $280 \mathrm{~nm}$. Note the thymine peak with a retention time of 72 min.

\section{DisCUSSION}

It is accepted that thymine-requiring mutants of many organisms can be produced in vitro by growth in the presence of thymine and trimethoprim (Stacey and Simson, 1965; Andrew, 1973). Because the available evidence suggested that normal mammalian tissues, blood and urine do not contain measurable quantities of thymine (Cleaver, 1967; Jaffe, McCormack and Meymarian, 1972; Then and Angehrn, 1974), the emergence of such mutants in vivo during trimethoprim therapy seemed unlikely. However, thy ${ }^{-}$mutants of several organisms have been isolated from patients treated with co-trimoxazole, and 
we have demonstrated that, in six such patients, the urine contained a thyminelike substance. The quantities detected in four urines were probably adequate to supply the growth requirements of the mutants from those patients (IK, AA, JS and JC). The amount in the urine from patient VS was adequate to supply the low-requiring organism (strain VS(1)a), but not the high-requiring organism (strain VS(1)b) isolated in mixed culture with it, and the amount detected in the urine of patient SS was not adequate to supply his high-requiring mutant. These were, however, all single random samples of urine, and higher levels may perhaps have been present at other times.

We have suggested (Maskell et al., 1976) that measurable levels of thymine in the urine of some patients with renal calculi and urinary-tract infection might result either from the breakdown of pus cells or from thymine production by living bacteria persisting in the stones. A similar explanation might apply in chronic chest disease with fibrosis and scarring (patient $\mathrm{M}$ ); in long-standing nephrostomy-wound sepsis (patients JE and OB), and in the chronic inflammatory cystitis that occurs in the presence of an indwelling catheter (patient CB), neurological impairment of bladder control (patients JC and KD) or vesico-colic fistula (patient VS). The suggestion that thymine is produced by living organisms persisting in stones or chronic inflammatory tissues is supported by our observation of " satellitism " in vitro. It seems that wild-type organisms can produce a factor that enables thymine-requiring mutants to grow, and that mutants with a low thymine requirement grow better and more quickly than those with a high requirement. However, E. coli strain NCTC10418 did not appear to supply the other growth factor needed by the mutant strains of Str. faecalis (JC, KD, EF and PH), and satellitism could be demonstrated only when IS agar was used as the culture medium. It is also possible that the mutant organisms themselves might be over-producers of thymine (K. A. Stacey, personal communication). Although the number of control specimens we were able to examine for thymine content was small, it seems unlikely that normal urine or urine with pus contains measurable levels of thymine; if, therefore, the persistent pyuria in the patients with stones and mutant infection is relevant, it is likely to be only one factor in a complex situation.

Eight of the nine patients from whom we isolated mutants between 1971 and the middle of 1975, and on whom we have reported previously (Okubadejo and Maskell, 1973; Maskell et al., 1976), had renal calculi associated with infection, and one had chronic chest infection. All except one had been taking co-trimoxazole for several months before the emergence of the mutant organisms; the one who had received only a short course of treatment (patient OK) was undergoing radiotherapy for carcinoma of the bladder at the time. However, since the middle of 1975 we have isolated an increasing number of mutants, some from patients similar to the original ones, but others from patients who had been taking co-trimoxazole for less than 1 month. Consideration of the mechanism of mutation to thymine requirement suggests a possible explanation for this. The mutation that occurs in response to trimethoprim is an alteration in the gene coding for thymidilate synthetase (Barner and Cohen, 1959); thy ${ }^{-}$mutants can no longer synthesise thymidilate from folates, and 
therefore require exogenous thymine for DNA synthesis. Organisms that have undergone this single mutation require more than $40 \mu \mathrm{g}$ of thymine per $\mathrm{ml}$ in minimal media (Stacey and Simson, 1965). Thymine combines with deoxyribose-1-phosphate to form thymidine; deoxyribose-1-phosphate is also catabolised to breakdown products by the agency of deoxyribose phosphomutase and deoxyribose-5-phosphate aldolase (Hoffee and Robertson, 1969). If the catabolism of deoxyribose-1-phosphate is blocked by mutation of one or both of these enzymes a pool will accumulate, and thereby lower the concentration of thymine necessary for a steady supply of intracellular thymidine. In this way, thy ${ }^{-}$mutants with a considerably lower thymine requirement could emerge. There is no evidence that trimethoprim acts against either mutase or aldolase, but it might favour the existence of thy ${ }^{-}$mutants, thereby allowing the selection of mutants that grow on lower levels of thymine from those that require high levels. The forward mutation rate for the loss of the enzymes concerned in the catabolism of deoxyribose-1-phosphate is likely to be about $10^{-4}-10^{-5}$ (K. A. Stacey, personal communication), and therefore low-thymine-requiring mutants would emerge. It is thus possible to postulate that organisms may undergo mutation to thy ${ }^{-}$in response to trimethoprim in vivo; initially they have a high thymine requirement, and, as this amount of thymine is unlikely to be available in normal tissues, they undergo thymineless death. The time-course of the earlier cases suggests that mutants did not emerge until wild-type organisms had been exposed to trimethoprim for several months; the patient $\mathrm{OK}$ was undergoing radiotherapy, and this might possibly have accelerated the mutation. Some of these organisms had a high and others a low thymine requirement, which was evidently supplied. The isolation of mutants from patients on short courses of treatment since 1975 suggests the possibility that mutation to thy- may be occurring more rapidly; if any thymine is present, the mutants might survive for a time even if their requirement is not completely supplied. The morphology of the organisms isolated after only a few days from patients JE and $O B$ suggested thymine deficiency. A rapid further mutation to low thymine requirement might then allow them to persist. Clearly this phenomenon could occur only in the presence of thymine; with the very widespread use of co-trimoxazole, the isolation of mutants is still rare, and, in our experience, confined to patients in whom either the persistence of organisms in tissue inaccessible to the antibacterial agent or the presence of chronic sepsis might provide the thymine source. If the mutants themselves are over-producers of thymine, the phenomenon could then become selfperpetuating.

The clinical significance of infection with thy ${ }^{-}$mutants is not yet clear, although evidence is accumulating that these organisms are pathogenic. Tanner and Bullin (1974) isolated a mutant from the blood of a pyrexial patient; patient EC in our series may be presumed to have died from mutant septicaemia, and most of the urinary-tract infections with mutants were accompanied by pyuria. During the past few months we have been isolating these organisms at a rate of $c$. one per month, considerably more often than during the previous 4 years; a careful watch has been kept throughout the 5 years since the first 
isolation, and we conclude that the phenomenon is occurring more frequently. This may have implications for the future usefulness of co-trimoxazole, especially as a long-term agent in the type of patient we have reported upon. It is essential that clinical laboratories should be aware of the existence of thy ${ }^{-}$mutants, that patients on long-term therapy should have regular bacteriological monitoring, and that co-trimoxazole should be stopped in patients from whom mutants are isolated. For patients on short-term therapy, there is usually a wide choice of alternative chemotherapeutic agents, and the choice should be made in the light of the sensitivity of the organism and the clinical circumstances. Sensitivity to agents other than sulphonamides and trimethoprim can be determined satisfactorily on CLED agar; this will be necessary as, of course, the mutants will not grow on the usual thymidine-deficient media. Patients who require long-term therapy present greater difficulties. Nitrofurantoin has been used successfully for long-term prophylaxis of urinary-tract infection (Bailey et al., 1971), but is ineffective against Proteus spp., and should not be used in patients with renal insufficiency. Two of the patients in the present series (IK and VS), who were treated with nitrofurantoin after mutants had been isolated, were subsequently given co-trimoxazole by doctors who were unaware of the previous mutant infection. Mutants were later isolated from one of them. Whatever decision is made about the treatment of each individual patient, it is clear that frequent bacteriological monitoring is essential.

\section{SUMMARY}

Clinical details are presented of 16 patients from whom thymine-requiring $\left(\right.$ thy $\left.^{-}\right)$mutants of pathogenic organisms were isolated; all had been treated with co-trimoxazole. The urine of six patients infected with thy ${ }^{-}$mutants contained levels of a thymine-like compound sufficient to support their growth. This might be the result either of the breakdown of pus cells or of thymine production by living bacteria that persist in stones or scar tissue, a suggestion supported by the observation of mutant growth " in satellitism" in vitro. Since 1975 we have isolated mutants from patients who have had short courses of co-trimoxazole, in contrast to those we reported upon previously, all except one of whom had had long courses. We are now isolating thy ${ }^{-}$ mutants more frequently than hitherto. Secondary mutations to a low thymine requirement may now be occurring more rapidly, thereby allowing more mutant organisms to survive. The clinical significance of infection with thymutants is not yet clear, but evidence is accumulating that they are pathogenic. Alternative chemotherapy is suggested for patients from whom such mutants have been isolated.

We are very grateful to Professor K. A. Stacey for advice, and for criticism of the manuscript.

\section{ADDENDUM}

Since writing this paper, a thymine-requiring strain of Proteus mirabilis has been isolated from pus from chronic osteomyelitis of the tibia. The patient had been treated with cotrimoxazole for 1 month before the isolation of the mutant. 


\section{REFERENCES}

ANDREW, M. H. E. 1973. Use of trimethoprim to obtain thymine-requiring mutants of Streptococcus faecalis. J. gen. Microbiol., 74, 195.

ArLINGer, L. 1971. Isotachophoresis in capillary tubes. Protides biol. Fluids, 19, 513.

Bailey, R. R., Roberts, A. P., Gower, P. E. AND De Wardener, H. E. 1971. Prevention of urinary-tract infection with low-dose nitrofurantoin. Lancet, 2, 1112.

Barker, J., Healing, D. and Hutchison, J. G. P. 1972. Characteristics of some cotrimoxazole-resistant Enterobacteriaceae from infected patients. J. clin. Path., 25, 1086.

BARNER, H. D. AND COHEN, S. S. 1959. Virus-induced acquisition of metabolic function. IV. Thymidilate synthetase in thymine-requiring Escherichia coli infected by $T_{2}$ and $T_{5}$ bacteriophages. J. biol. Chem., 234, 2987.

Cattell, W. R., Chamberlain, D. A., Fry, I. K., McSherry, M. A., Broughton, C. and O'GRADY, F. 1971. Long-term control of bacteriuria with trimethoprim-sulphonamide. Br. med. J., 1, 377.

Cleaver, J. E. 1967. Thymidine metabolism and cell kinetics. Frontiers of biology series, edited by A. Neuberger and E. L. Tatum, vol. 6, Amsterdam, p. 60.

Clowes, R. C. AND Hayes, W. 1968. Experiments in microbial genetics, Oxford.

CowAN, S. T. AND STeEL, K. J. 1966. Manual for the identification of medical bacteria, London.

EVERAERTS, F. M. AND BECKER, J. L. 1976. Isotachophoresis: theory, instrumentation and applications, Amsterdam.

HayeK, L. J. AND Netherway, J. 1976. Thymine-requiring bacteria. Lancet, 1, 1080.

Hoffee, P. A. AND Robertson, B. C. 1969. 2-Deoxyribose gene-enzyme complex in Salmonella typhimurium: regulation of phospho-deoxyribomutase. J. Bact., 97, 1386.

JAFFe, J. J., MCCoRmaCK, J. J. AND Meymarian, E. 1972. Comparative properties of schistosomal and filarial dihydrofolate reductases. Biochem. Pharmac., 21, 719.

LACEY, R. W. AND LEWIS, E. L. 1973. Is co-trimoxazole bactericidal in sputum? Br. med. $J ., 4,165$.

Lowbury, E. J. L., KIDSON, A. AND LILly, H. A. 1964. A new selective blood agar medium for Streptococcus pyogenes and other haemolytic streptococci. J. clin. Path., 17, 231.

MACKeY, J. P. AND SANDYS, G. H. 1966. Diagnosis of urinary infections; clinical aspects. Br. med. J.,1, 1173.

Maskell, R., Okubadejo, O. A. and Payne, R. H. 1976. Thymine-requiring bacteria associated with co-trimoxazole therapy. Lancet, $1,834$.

Okubadejo, O. A. AND Maskell, R. M. 1973. Thymine-requiring mutants of Proteus mirabilis selected by co-trimoxazole in vivo. J. gen. Microbiol., 77, 533.

SANDYS, G. H. 1960. A new method of preventing swarming of Proteus spp. with a description of a new medium suitable for use in routine laboratory practice. J. med. Lab. Technol., 17, 224.

Smellie, J. M., Grüneberg, R. N., Leakey, A. AND Atkin, W. S. 1976. Long-term lowdose co-trimoxazole in prophylaxis of childhood urinary tract infections: clinical aspects. Br. med. J., 2, 203.

StACEY, K. A. AND Simson, E. 1965. Improved method for the isolation of thymine-requiring mutants of Escherichia coli. J. Bact., 90, 554.

TANNER, E. I. AND Bullin, C. H. 1974. Thymidine-dependent Escherichia coli infection and some associated laboratory problems. J. clin. Path., 27, 565.

TAPSAll, J. W., Wilson, E. AND HARPER, J. 1974. Thymine dependent strains of Escherichia coli selected by trimethoprim-sulphamethoxazole therapy. Pathology, 6, 161 .

Then, R. AND Angehrn, P. 1974. Co-trimoxazole resistance. Br. med. J., 1, 78. 